\title{
Training and Instruction Skills Through the Test of Time
}

\author{
Sharon Tzur ${ }^{1}$, Prof. Nitza Davidovich ${ }^{1} \&$ Dr Adi Katz ${ }^{2}$ \\ ${ }^{1}$ Faculty of Social Sciences and Humanities, Ariel University, Israel \\ ${ }^{2}$ Industrial Engineering \& Management Department, Shamoon College of Engineering, Israel \\ Correspondence: Nitza Davidovich, Faculty of Social Sciences and Humanities, Ariel University, Israel.
}

Received: April 6, 2021

Accepted: November 3, 2021

Online Published: November 5, 2021

doi:10.5430/ijhe.v11n3p15

URL: https://doi.org/10.5430/ijhe.v11n3p15

\begin{abstract}
This study involves e-learning skills via educational software, compared to instruction via educational software with the mediation of an instructor. In the last two decades, the role of the teacher-lecturer has changed, from teaching to guidance and instruction. The technological tools have changed the nature of the learning space and the manner in which the teacher interacts with his students.

Educational software is a collection of digital pages, packaged as a learning unit, and is a common tool for delivering self-instruction in academia on a range of issues. This is despite the fact that the effectiveness of this tool in academia has not yet been tested. In addition, the educational software is a technological tool but it is not being updated regularly, therefore the development of the topics in educational software is low.

The key motif of technological advancement is to enable constant updates, and therefore, the effectiveness of this learning tool, which has the potential of countering the need for the dynamics of content transfer with its static nature, must be examined. The current study aims to examine the use of this tool in teaching and instruction, and to examine the ways to bridge over this gap of a "static" tool and a "dynamic" learning world.

The study focuses on a case study in the Israeli Air Force and integrates instruction with technologies means. We have looked into the skills of e-learning through educational software, as well as the contribution of the instructor to the teaching process. The study's literature reveals that e-learning focuses on the cognitive aspect of learning and on the knowledge of the instruction field. Yet there are studies that engage in reinforcing the in-person communication, meaning, the significance of a "face-to-face" encounter between the student and his instructor. We examined the probability and the extent of the added value of the teacher/instructor in e-learning through educational software. An examination of e-learning through educational software is conducted by a test that consists of questions broken down into levels according to the STEM Model.

The findings of the study demonstrate the contribution of educational software as a means of instruction, when it is combined with an in-person encounters between the students and their instructor. We found that combining the in-person meetings with the educational software practice has vastly improved the motivation of the technicians in training, their learning experience and the learner's ability to understand the learning material.

The results of our study shed a spotlight on the instruction, which are a major part of the teaching process in general, as well as the use of educational software as a relevant and applicable mean in the training process in particular. The case study, conducted in the Israeli Air Force, which guides the training processes that are held in the army, is the first case study of its kind, which tracks the use of educational software as a means of instructional work. Our assumption is that training work using educational software has a high influence in the context of teaching and training in different and diverse institutions and organizations, such as in academia.
\end{abstract}

Keywords: e-learning, educational software, technological training, in-person instruction

\section{Introduction}

In the Twentieth Century, the higher-learning system has undergone a major transformation - from a limited elitist system to a system that is geared toward the masses (Trow, 1973). It is manifested by the enormous growth in the number of students in Western societies (Davidovitch et al., 2012). The transformations that have occurred in the Israeli high-learning system have provided access to higher education and degrees in general, as well as to more advanced degrees (Davidovitch \& Sinuani-Sterm, 2014; Cohen \& Davidovitch, 2020). 
In the past two decades, a growing number of e-learning technologies were introduced, which changed the teaching nature in the classroom, thereby transforming the teacher a persona that mediates the technological-learning methods to the students (Waldman 2007; Nachmias \& Mioduser, 2001). The use of digital teaching tools as a central work method at an ever-expanding scope in the various educational systems was already integrated in schools, colleges and universities before Covid-19, and probably thereafter (Davidovitch \& Wadmany, 2021; Nachmias \& Mioduser). Learning via technological means became accessible and preferred for various organizations and students, while this type of learning raises learning and instructional challenges in terms of learning experience, the motivation to learn and interpersonal communication. Therefore, some studies recommend to combine learning via technological tools with traditional in-person learning, which is based on social-learning meetings in classroom settings, personal support from teachers, lecturers and instructors. The instructor also has the role of operating and explaining the learning material via the online system, completing relevant information, exposing the learners to higher-learning levels, while providing examples (Davidovitch \& Eckhaus, 2020; Sue et al., 2005; Davidovitch \& Wadmany, 2021; Nachmias \& Mioduser, 2001).

Studies that were conducted on learning in formal and non-formal environments indicate that frontal learning only has a minor role on the individual's learning experience throughout his lifetime: The role of formal learning in conveying the learned information stands at approximately $19 \%$ by the end of the twelfth grade, and that rate shrinks to $8 \%$ in the first degree and to 5\% in the second degree (Chen \& Bryer, 2012). In addition, studies point to e-learning's capacity to improve the learning processes and the learners' achievements (Joubert, 2013; Laborde \& Straesser, 2010) as the chief goal of the learning environments and online practice is to help and promote the learner to grasp a specific topic or achieve a specific learning objective, while placing the learner in the center of the experience (Cicognani, 2000).

The crisis of Covid-19 has deeply influenced learning institutions from around the globe and shook things up to a considerable degree. The epidemic forced elementary-schools, high-schools and higher-learning institutions to be shut down temporarily. Various schools, colleges and universities completely halted in-person instruction (Ben-Amram \& Davidovitch, 2021). The educational institutions were badly struggling to cope with the challenging situation and these circumstances made them realize that planning for extreme-cases scenarios was needed, such as not being able to teach in-person because of security concerns or a global pandemic. There was a need for an urgent response throughout the educational systems, including academic institutions. Therefore, in addition to claims that favored online learning such as: accessibility at anytime and anywhere and flexibility when performing the instruction (Davidovitch \& Eckhaus, 2020) there was another claim that online learning is used as an essential response in times of crisis such as a war or global epidemic. The combination of "face-to-face" meetings and lectures with technological tools may generate combined interactive learning and heighten the learning potential of the students.

The lecturers/instructors can develop new skills among the learners, such as those that will foster learning processes throughout their lifetime. The Covid-19 crisis also forced governments from around the world to recognize the growing significance of online learning in a dynamic world that faces different kinds of major scenarios (Dhawan, 2020; Eckhaus \& Davidovitch, 2019).

Technology Based Training is effectively a form of instruction that mainly relies on the Internet. This method is fast, available and relatively cheap since the training resources are found online and are accessible to learners from everywhere and at any time. Therefore, this method creates a relatively high level of commitment from the learner's part to the learning process and is manifested by a higher level of learning and performance (Cotton, 2008; Kruse \& Keil, 2000). Computer Assisted Instruction is based on a computer and not on the resources of the internet. This type of instruction is more limited, as it binds the learner to physically face a computer screen and watch, for example, videos that are saved on the computer itself (Schmeeckle, 2003).

Motivation as a whole, especially internal motivation, empowers learning because the state of internal motivation by its very definition is a very positive emotional state; inner motivation is coupled by feelings of interest or pleasure, and is often accompanied by a flow experience between the learner with the learning material and the learning methods (Csikszentmihalyi, 1990). In addition, internal motivation contributes to shaping an identity, as it helps an individual find what really interests him and with which activities he identifies with and feels at ease (Irvine, 2018). there is a connection between internal motivation and the interpersonal atmosphere - the social atmosphere at school, which is significant as it indicates that promoting internal motivation is an important topic not only to those who are interesting in the students' learning or self-development, but also to those who are interested in their social development (Bromberg et al., 2010, Ben-Amram \& Davidovitch, 2021). Motivation makes learning more efficient 
and allows the student to stay focused and perform tasks that would help him reach his objective. The teacher, as the instructor, has a major role in generating motivation for learning (Van et al., 2016).

One of the key aspects for advancing students in an online environment is the emotional aspect (Ben-Amram \& Davidovitch, 2021). Many students often struggle in the learning processes because they lack the motivation or self-confidence to apply the skills they acquired. In addition, these students find it very difficult to restrain associations that are irrelevant instead of focusing on the problem they are facing (Hannula, 2006). Therefore, it is critically important to reinforce their motivational-emotional aspect and raise their self-confidence so that they would be able to better understand the learning material, which can be achieved through the instructor's mediation (Ross et al., 2016).

One of the common technological tools for instructional practice, also in the academic world, is educational software, which is a collection of digital pages that is packaged as a learning unit, including texts, audio files, video files and photos. Educational software often includes interactions that enable the learner to answer questions or perform any tasks throughout the learning process. Often, progressing through the educational software and even completing it depends on providing the right answers to questions.

The educational software is characterized by high technological architecture, but they do not promote personal contact, do not invoke feelings, and do not enable the learner to control the training process. In addition, they are not being regularly updated.

In the past decade, academic institutions have started to use this educational software in a range of trainings in order to facilitate students' self-learning on various topics such as offering first aid, sexual-harassment prevention and safety procedures. The main goal of using educational software is to save money, save learning-spaces resources, and offer flexible options to the students to learn at the place and time of their choice. As mentioned, in the era of Covid-19, when it was often not possible to conduct in-person learning, this tool became even more common (Dhawan, 2020; Davidovitch \& Wadmanay, 2021).

The effectiveness of training through educational software has not yet been studied in academia. In addition, the educational software is a technological tool that is very expensive to create and update, therefore it is not being regularly updated. In a dynamic world, where changes often occur, this tool, which is not up to date on topics, may pose a serious problem. This is a paradox since technological tools are supposed to update us with the most recent and newest information anywhere and at any time (Resta \& Shonfeld, 2013), so how can this gap be bridged? That and other questions have not yet been studied in academia.

In this study, we focused on a case study of the Israeli Air Force. By being a high-technology army corps, the Air Force has integrated training by technological means in the last two decades. Most trainings are conducted by technicians in a computerized setting and do not involve a human trainer. The Air Force has not examined the effectiveness of these trainings and the effectiveness of integrating the trainer's instruction in e-learning with the added value of the trainer-instructor in these trainings in particular.

The goal of the current study is to examine and assess the effective use of educational software, with an emphasis of integrating the trainer-instructor in online learning. We examined the effectiveness by a controlled study with two training groups: The first group studied through educational software alone and the second group studied through educational software with the mediation of a instructor's/trainer's. The study also included a knowledge-erosion test after a few months after the training, and the effectiveness of the training was also examined in terms of learning levels according to Bloom's Taxonomy (knowledge, understanding and application) and based on the Engineering Mathematics Science Theory (STEM Theory). The study's findings are highly relevant for academic institutions that are considering the method of using the educational software as a learning tool, in view of its disadvantages, and mainly due to the fact that it is not updated regularly and does not generate communication and control in the training process.

\section{Literature Review}

Learning is an internal process of acquisition, expansion or improvement of knowledge, understanding, ability or skill. In that manner, learning can be described as a change and growth in any field. Learning is a process of a relatively stable change in behavior. This change cannot be directly observed, and for that reason learning is defined through its results that are expressed through external observable behavior. Learning leads to a relatively permanent change in behavior or the potential for to the individual's behavior (Kaniel, 2006). The learner in the traditional era is a passive learner, as the knowledge is mostly conveyed unilaterally. The teacher/lecturer current age is at the heart of teaching-learning. Students in traditional learning, in most cases, did not know about the learning-discovery 
experience, and often did not experience the pleasure of creation. Usually they did not take responsibility for knowledge - experiences with inherent potential for positive feelings (Kaniel, 2006).

Distant learning and distant education have a history from the mid Twentieth Century (Cohen \& Davidovitch, 2020). For example, educational institutions in Britain planned new types of open courses in various disciplines, with the aim of creating an alternative to the traditional "face-to-face" form of education, which was especially geared to those who could not learn at school for social or financial reasons. These plans effectively facilitated the number of students to increase significantly. Since 2012, many academic programs allow an unlimited number of students to be accepted. These programs offer adults and working people to participate in e-learning courses - which integrate online and in-person learning. As for example in the Massive Open Online Courses (MOOC).

The Covid-19 epidemic has shut down schools and universities in many countries for extended periods of time, making distant learning and distant education a critical path for guaranteeing the educational and learning continuity of the students in schools and universities. Most activities were conducted via e-learning platforms or via applications that include video learning such as Zoom and Google Meet. In some countries like UK, the fact that digital tools and virtual-reality programs were available, enabled the rapid resumption of learning (Domenici, 2020).

The e-learning environment is considered a better alternative to the traditional one. Online courses and learning frameworks that are included in the e-learning environments became more common. They contain many multimedia components and are connected to databases and experts that provide technical and pedagogical solutions. Nachmias \& Mioduser (2001) point to the advantages of the online environment, as such that merges between the three dimensions: A virtual-reality community (the social dimension) that remains in a virtual-reality environment (the technological dimension) and creates educational ideas (the educational dimension). The professional literature highlights the complexity of the fully-utilized online environment and its assimilation in the educational systems (Davidovitch \& Wadmany, 2021; Waldman, 2007).

Information technology, digital technology and social networks have a major impact on learning behavior, especially in youths who are well versed in them. These diverse means of media facilitate the development of social networking that encourages an active and sharing social learning (Almeida et al., 2013). Professional changes throughout one's lifetime may frequently occur and will require an update of the skills that are necessary for learning in a technological environment. Technology will have a major role in providing learning opportunities at any time, which will be focused and customized (Kidd \& Chen, 2011).

One of the changes in the online teaching environment is the teacher's role in the learning process. The traditional teacher is described as the provider, conveyor and source of information, while the online teacher is described as the instructor and the information mediator (Davidovitch \& Eckhaus, 2021, Nir Gal, 2000). In online teaching, the teacher undergoes a process of internal growth as he transforms from a lecturer to an instructor. As such, he should promote a range of assessment processes and make an effective use of the learning-management system. His new role includes performing complex tasks, conducting a shared learning assessment, developing new standards for evaluating the learners, while creating new knowledge (Sun et al., 2008).

The teacher's assessment methods in the online era are characterized by creating standards for self-assessment, peer assessments and self-feedback. In addition, in e-learning, the student learns by self-experimentation and documentation, coping with new situations, diverting new learning activities, critical judgment and decision-making. teaching practices should consist of assigning tasks that encourage a structured response and promote learning by the learner's self-esteem and self-feedback (Eyal, 2010). Therefore, there is a need to appropriately train teachers and lecturers, which will foster professional development, acquired pedagogical knowledge and the relevant technological knowledge (Yuen \& Ma, 2008).

The Media Naturalness Theory claims that the media's naturalness level is examined by five features: (Weiser et al., 2016) Being present in a shared physical location, high synchronization that facilitates a spontaneous reaction to stimulations, recognition and conveyance of facial expressions and the conveyance of a body language, and the possibility of listening to natural speech and produce it. Based on this theory, one must aspire that the media being used will be at the highest naturalness level and approached as close as possible the naturalness level that occurs in in-person learning. Sometimes The more technologically advanced the medium and with its help it is possible to communicate simultaneously in a greater number of channels, the greater the cognitive effort required of the learner and the teacher and the quality of learning is impaired. (Weiser et al., 2016). The Media Richness Theory (MRT) is used to evaluate various types of communication media according to their richness. Based on MRT, communication that requires a longer time for mutual understanding is generally less rich. Therefore, media with richer communication is normally suited to ambiguous and irregular messages, while a poorer media (less rich) is more 
suited to regular and unequivocal messages (Daft \& Lengel, 1984). Sometimes, training through technological means alone will be sufficient and sometimes reinforcement is required from a trainer in in-person communication. In addition, MRT shows that in simple situations, a relatively poor media is sufficient (for example educational software only) while in more complex content/topics a richer media is required, such as in-person communication with a trainer (Chang, et al., 2017). Furthermore, in obscure and more complex situations, there is a need for contextualization, meaning, adding more layers of information in order to clear up messages that may be wrongly interpreted. Studies indicate that this is the case for any interpersonal communication context (Katz \& Te'eni, 2014) including online learning (Katz \& Kedem-Yemini, 2021). One of the dominant methods to do so is with a trainer who creates in-person communication (Chang, et al., 2017).

Motivation is a psychological process that provokes alertness, guidance and perseverance of voluntary action towards reaching a goal. The term "motivation" relates to the need to invest time and effort in a specific activity, even if difficulty is involved, or it involves high costs and failures. While internal motivation relates to motives involving an individual or an action he is engaged, external motivation relates to motives that involve the environment and, such as the desire to receive reward or the desire to avoid punishment (Richard \& Desi, 2011). Internal motivation empowers learning since it is a very positive emotional state; internal emotional motivation is accompanied by feelings of interest or pleasure and often the flow experience (Csikszentmihalyi, 1990). Internal motivational situations are pleasant and desirable in emotional terms and the teacher's role is critical for creating such motivation (Irvine, 2018).

The researcher Schmeeckle (2003) examined e-learning in order to provide a comprehensive assessment of training effectiveness and the differences in learning motivation among the two types of training - e-training versus in-person training. His study found no major difference between in-person training to e-training in terms of the learning's effectiveness. An additional study by Weiser et al., (2016), compared between in-person learning and learning in two online environments - one-sided video (only the instructor can see the students) and two-sided (the instructor and students can see each other) to examine the impact of media naturalness. The results showed that the participation level of students in many cases predicts their level of success. Therefore, the students' participation in learning is critical. Learning is normally achieved by the in-person training, in which the trainer evokes an interest, asks questions and provides practical examples from daily life. Weiser's study found that there is no clear advantage to in-person learning or the naturalness level of the communication channel and that the lecturer's instruction style mainly impacts active participation.

\section{Methodology}

We have examined the contribution of the trainer in e-learning in terms of two theories that dealt with learning products and outputs. We followed Bloom's Taxonomy to examine the effectiveness of learning at various levels (knowledge, understanding and application), and the general teaching goals according to STEM, in order to look into the impact that training has on learners from different perspectives.

Bloom's Taxonomy (1956) is a tool used to classify learning assignments based on their level of thinking. It consists of six thinking levels in an incremental manner, from the simple to the more complex, so that obtaining a high cognitive level is contingent on obtaining its former levels (Melamed, 2013). Bloom's Taxonomy was intended to achieve two main goals: Planning a more effective learning and examining learning-caused achievements. In the current study, we use the first three grading levels of Bloom's Taxonomy: Knowledge - the most basic level, which consists of the ability to retrieve bits of information, facts and terms from our long term memory; Understanding - a higher level that demonstrates the ability to interpret and translate the knowledge to meaning. Understanding is based on knowledge but requires additional thinking; and application - a level in which the learner is also required to provide solutions for new situations. Application is based on the knowledge and understanding but also requires a coping ability and decision making about the response or action to new situations (Melamed, 2013).

STEM Theory (short for Technology Engineering Mathematics Science), maintains that learning products should be clear, easy to assess and not obscure. It describes measurements that focus on the final result of learning in performance terms. STEM defines general teaching goals such as the abilities to apply knowledge, plan tasks and assignments as a result of learning, analyze and interpret information learned about the system, plan any system in view of realistic constraints (financial, environmental, social, political and ethical constraints), function in multidisciplinary teams, troubleshoot in a team and collaborative work, identify and to phrase and resolve problems and glitches in the specific system as a result of learning (Davidovich \& Shiller, 2016).

The current study was conducted at the Israeli Air Force and with the aim of examining the trainer's contribution to e-training, as the selected tool is educational software. The effectiveness was also examined for the short term 
(immediately after performing training) Effectiveness is determined by tests divided into questions that represent different levels according to the first three stages of Bloom's Taxonomy, in addition, questionnaires that examine the training's effectiveness and the motivation of trainees according to the STEM model (Davidovich \& Shiler, 2016). The study sought to allow organizations and academic institutions to examine the use of educational software and the manner of dealing with the drawbacks of this tool.

The study's assumptions are: At the knowledge level, there will be no difference in the learning effectiveness between training via educational software for training purposes in comparison to an educational software combined with a trainer. This is in line with Schmeeckle (2003), who examined the learning effectiveness between in-person learning to e-learning and found no significant differences between the two types of trainings. On the other hand, e-training, combined with a trainer, will be more effective at the understanding and application levels of Bloom's Taxonomy, since these topics in training also include ambiguous and irregular messages (Daft \& Lengel, 1984). According to the Media's Naturalness Theory, face-to-face communication in in-person training is favored over e-training (Weiser et al., 2016). In addition, according to STEM (Davidovich \& Shiler, 2016), e-training in combination with a trainer will be more effective since the trainers will facilitate face-to-face communication and strengthen the richness and the learning experience (Chang, et al., 2017). Regarding knowledge erosion, we assume that there will be more erosion among the group that studied with educational software without a trainer's mediation, since the in-person learning will provide a bilateral communication. The trainee's involvement in learning is critical and will provide for a deeper understanding, therefore also for a longer-term memory (Weiser et al., 2016).

Fifty six Air Force technicians participated in the current study. Participants were randomly divided into two equally-sized groups and were trained on the topic of F16 safety. The study was held in two stages. At the first stage (hereafter, stage A), we compared the training's effectiveness between a situation of learning educational software with the mediation of a trainer, and a situation of an educational software without a trainer. An analysis of the learning products was made using Bloom's Taxonomy in the following manner: After the training, we tested the performance of the participants in each group using identical tests. The test was a 30-item questioner at various levels: 10 questions on a knowledge level (such as, "What the pressure in the system is?"), 10 questions on an understanding level (such as, "What is the system's objective?") and 10 questions on an application level (such as "What would be an appropriate response in case something happens?"). The definitions of the participating technicians and the random division guaranteed the participating population's uniformity. In addition, a learning-products' test was held according to the STEM model with a questionnaire that included an item for each of the 11 learning products defined according to the model on a Likert scale from 1 to 6 from low to high (see Appendix A). The second stage was held four months after the training phase. Our goal was to examine the knowledge erosion in training effectiveness between learning educational software with the mediation of a trainer, and a situation of an educational software without a trainer, over time. In the second stage (hereafter, stage B), we tested the technicians again to examine their knowledge in terms of Bloom's Taxonomy levels. The experimental setting is fully described in (Tzur, Katz \& Davidovitch, 2021).

\section{Findings}

\section{Stage A results}

The grades in the test's questions when training with an educational software alone were low $(\mathrm{M}=6.63, \mathrm{SD}=0.40)$ compared to the training situation with an educational software mediated by a trainer's mediation $(\mathrm{M}=7.34, \mathrm{SD}=0.44)$.

At the knowledge level, according to Blooms Taxonomy, the scores in the two methods were almost identical: the results were $(\mathrm{M}=7.3, \mathrm{SD}=0.49)$ in the group that was trained with educational software alone, and $(\mathrm{M}=7.32, \mathrm{SD}=0.48)$ in the group that learned educational software with the mediation of a trainer.

At the understanding and application levels, there was a clear advantage to learning educational software with the mediation of a trainer. At the understanding level, the grades in the educational software in combination with the trainer were higher $(M=7.75, S D=0.45)$ compared to the use of educational software alone $(M=6.54, S D=0.47)$. At the application level, the grades in the group that was trained with educational software in combination with the trainer were also higher $(M=6.96, S D=0.45)$ compared to the use of educational software alone $(M=6.07, S D=0.48)$.

We used the Mann-Whitney test to examine the differences between the two groups, since it is a test suited for relatively small samples. Our results showed that using an educational software with the mediation of a trainer is significantly better $(\mathrm{U}=75.50, \mathrm{p}<.001)$. In terms of the STEM model, training with educational material alone showed low results $(\mathrm{M}=2.95, \mathrm{SD}=0.54)$ compared to training with an educational material in combination with a trainer $(\mathrm{M}=3.47, \mathrm{SD}=0.35)$. 


\section{Stage B results:}

Based on the tests' results of stage B, in terms of Bloom's Taxonomy measures, after four months, in all levels, the group that studied with a trainer's mediation achieved better result, compared to the group that studied with an educational software's training alone.

At the knowledge level, the grades were high in the group of educational software with a trainer's mediation (M=6.34, $\mathrm{SD}=0.46)$ compared to the group that was trained with an educational software alone $(\mathrm{M}=5.55, \mathrm{SD}=0.58)$. At the understanding level, we found similar results. In the group that was trained with an educational software with a trainer's mediation ( $\mathrm{M}=6.78, \mathrm{SD}=0.44)$ compared to compared to the group that studied with an educational software's training alone $(\mathrm{M}=5.15, \mathrm{SD}=0.71)$. Similarly, at the application level the results were $(\mathrm{M}=6.34, \mathrm{SD}=0.46)$ compared to $(\mathrm{M}=5.05, \mathrm{SD}=0.27)$.

When comparing the differences in grades of the second-stage tests according to Mann-Whitney, educational software with a trainer's mediation achieved better results $(M=6.49)$ than software alone $(M=5.25)$ and at a very high significance level $(\mathrm{U}=74.50, \mathrm{p}<.001)$.

When examining Knowledge erosion of the grades according to the three levels, the grades in the knowledge level was lower in the group that only learned through educational software (1.75) than in the group that learned with educational software with the trainer's mediation (0.98).

Changes in Friedman's statistics (used as a non-formal test) was $25(\mathrm{p}=0.00)$ for the group that learned through educational software alone and was $15.2(\mathrm{P}=0.00)$ for the group that learned through a trainer's mediation.

The grades for the understanding level was lower in the group that studied through educational software alone (1.37) than the group that studied with educational software with a trainer's mediation (0.97). Friedman's statistics was 19 $(\mathrm{p}=0.00)$ for the group that studied through a trainer's mediation.

The grades on the application level were lower in the group that studied with educational software alone (1.02) than the group that studied with educational software with a trainer's mediation (0.62). The differences between the grades after four months were the most significant at this level. Friedman's statistic was $18(\mathrm{p}=0.00)$ for the group that studied through educational software alone $(\mathrm{p}=0.00)$ and 13.2 for the group that studied with educational software with a trainer's mediation.

\section{Summary of the Trial's Findings}

The findings of the tests' results according to Bloom's Taxonomy:

The knowledge level - at Bloom's basic level, the results were almost identical, meaning, that an educational software in nearly identical to a situation without the need of a trainer's intervention. This result is consistent with the study's assumption.

The understanding and application levels - at the higher levels according to Bloom, the results for the educational software alone were much lower compared to the learning situation that combined a trainer with an educational software. In the latter, understanding vastly improves. These Results can be explained by the trainer's focus on helping his trainees understand the material and not just remember data. The trainer is present in order to ensure that understanding has been achieved and may provide answers to questions that reflect misunderstanding. In addition, according to the Media Naturalness Theory, a higher naturalness level, which enabled face-to-face training, reduces the learner's cognitive effort and increases the learning quality (Weiser et al., 2016). The Media Richness Theory maintains that a richer communication is more suited to complex and ambiguous messages as in the understanding and application level. Therefore, for learning at those levels it is not enough to contend with educational software alone and training should be fostered by face-to-face communication with a trainer (Daft \& Lengel, 1984). Furthermore, a trainer mediates the educational software, amongst others by using contextualization. In other words, she or he adds more layers of information beyond the basic message being conveyed by the educational software in order to clarify things that may be misinterpreted. Such a strategy, as mentioned, is significant in online learning (Katz \& Kedem-Yemini, 2021). In addition, the trainer situation forms bilateral communication that increases the trainees' level of participation. A trainer may motivate active participation by generating interest and by asking questions. This communication mode predicts in many cases the trainee's success, since it enables better understanding of the studied topic (Weiser et al., 2016).

In summary, if knowledge acquisition is required only at the most basic level of Bloom's Taxonomy, an educational software is sufficient, and is considered as an effective and convenient tool for trainees. However, if a higher level of 
understanding and application is required, a trainer, combined with an educational software is essential in order to provide the best results.

\section{The findings of the questionnaires according to the STEM Model}

In the STEM Model, learning through educational software alone received lower grades compared to educational software that is mediated by a trainer. Referring to assistance and instilling knowledge, the two studying conditions received similiar grades with a slight edge for educational software. The possible explanation for this finding is that from the trainees' point of view, educational software is considered a sufficient tool for conveying information and they do not feel the need for mediation when they are working with it. In terms of the ability to analyze tasks, and analyze and interpret data, educational software, in combination with a trainer, received lower grades. The key advantage of learning through educational learning in combination with the trainer can be seen in the broad-understanding question on the systems that were presented. For the question of deep understanding, the trainer probably helped trainees to reply successfully.

The objective of Stage B was to examine knowledge erosion to evaluate the training's effectiveness not only for the short term but also for the relatively long term. As we expected, there was an erosion after about four months. The level of erosion on the general level was higher in the learning group that used the educational software alone compared to the group that had an educational software combined with a trainer. This result can be explained by the trainer's emphasis on understanding the meaning of the studied material and the fact that semantic knowledge is stored in long term memory over time (Shneiderman \& Mayer, 1979). The trainer situation enables a bilateral communication that facilitates a higher level of participation by the trainees, that may generate an interest and raises questions. By doing so, the trainer puts an emphasis on understanding and not only on knowledge. This increases the probability to preserve more learning material in memory, and therefore decreases erosion (Weiser et al., 2016).

\section{Recommendations}

We examined the effectiveness of e-learning for the immediate term and long term by using the STEM Model (Davidovich \& Shiler, 2016) and through tests that examined the effectiveness of training at three levels according to Bloom's Taxonomy. We found that educational software is a convenient method when used as a single tool to perform learning. A combination of a trainer that mediates the educational software to students is highly valued. Most criteria being measured for a trainer's mediation have a major contribution in training through educational software even on the learning-achievements level as received by the tests' results in terms of Bloom and even in the subjective sense of a learning experience and the different perspectives of learning as received by the results of the questionnaires. Our conclusion is that the Air Force and academic institutions are recommended to make Teaching methods should be tailored to the specific learning objectives of the training. When the training requires only to convey information, the educational software is an effective and cost-saving tool. Yet, when the training requires a high level of understanding, training becomes more intricate and motivation needs to be stimulated and facilitate trainees' participation as well as making a connection to the training objectives, it is important to combine a trainer in the learning process. We highly recommend to examine the educational software every few months in order to ensure that it is still relevant to the training material. Otherwise, there is need to update it.

This case study of learning through educational software, under the trainings of the Israeli Air Force, was conducted on a high-quality group. We recommend to conduct future studies on the impact of educational software in other groups, to understand its effectiveness, especially due to the increasing use of technology for learning following the corona Epidemic.

\section{References}

Almeida, C. M. V. B., Santos, A. P. Z., Bonilla, S. H., Giannetti, B. F., \& Huisingh, D. (2013): The roles, perspectives and limitations of environmental accounting in higher educational institutions: an emergy synthesis study of the engineering programme at the Paulista University in Brazil. Journal of Cleaner Production, 52, 380-391. https://doi.org/10.1016/j.jclepro.2013.03.008

Ben Amram, M., \& Davidovitch, N. (2021). Teachers Attitude Towards E-Teaching during Covid-19. Emerging Sources. laplage em revista. Publisher: Univ Fed Sao Carlos, Rodovia Washington Luis, San Carlos, Sao Paulo, Brazil, 7(2), 13-32. ISSN: 2446-6220. https://doi.org/10.24115/S2446-6220202172678p.13-32

Bromberg-Martin, E. S., Matsumoto, M., \& Hikosaka, O. (2010). Dopamine in motivational Control: rewarding, aversive, and alerting. Neuron, 68(5), 815-834. https://doi.org/10.1016/j.neuron.2010.11.022 
Chang, C. C., Liang, C., Chou, P. N., \& Lin, G. Y. (2017). Is game-based learning better in flow experience and various types of cognitive load than non-game-based learning? Perspective from multimedia and media richness. Computers in Human Behavior, 71, 218-227. https://doi.org/10.1016/j.chb.2017.01.031

Cicognani, A. (2000). Concept mapping as a collaborative tool for enhanced online learning. Educational Technology \& Society, 3(3), 150-158.

Cohen, E., \& Davidovitch, N. (2020). The Development of Online Learning in Israeli Higher Education. Journal of Education and Learning, 9(5), Published by Canadian Center of Science and Education. Canada. https://doi.org/10.5539/jel.v9n5p15

Cotton, K. (2008). Computer-assisted instruction. Encyclopedia of Special Education, 2, 514-520. https://doi.org/10.1002/9780470373699.speced0481

Csikszentmihalyi, M. (1990). Flow: The Psychology of Optimal Experience. Journal of Leisure Research, 24(1), 93-94. https://doi.org/10.1080/00222216.1992.11969876

Daft, R. L., \& Lengel, R. H. (1984). Information Richness: A New Approach to Manage Information Processing and Organizational Design. Research on Organizational Behavior, Greenwich, Management Science, 13(5), 554-571.

Davidovitch, N., \& Eckhaus, E. (2021). The lecturer as supervisor: The effect of assessing the abilities of candidates for academic supervision on supervision outcomes. Laplage em Revista, 7(1), 133-141. ISSN: 2446-6220. https://doi.org/10.24115/S2446-6220202171278p.133-141

Davidovitch, N., \& Wadmany, R. (2021). 2020 - The Lecturer at a Crossroads of Teaching and Learning in Academia in Israel. Journal of Education and e-Learning Research, 8(3), 281-289. Asian Online Journal Publishing Group. USA. https://doi.org/10.20448/journal.509.2021.83.281.289

Davidovitch, N., \& Eckhaus, E. (2020). The Profile of the Supervising Lecturer: On the Association between Supervision Outputs and the Nature of the Supervision. Higher Education Studies, 10(4), 1-62. ISSN 1925-4741. Canadian Center of Science and Education. Toronto, Canada. https://doi.org/10.5539/hes.v10n4p62

Davidovitch, N., \& Shiller, Z. (2016). Skill-Based Teaching For Undergraduate STEM Majors. American. Journal of Engineering Education (AJEE), 7(1), 29-36. https://doi.org/10.19030/ajee.v7i1.9683

Davidovich, N., Sinuany-Stern, S., \& Iram, Y. (2012). The Price of Success: Some Consequences of Increased Access to Higher Education in Israel. Cross-Cultural Communication, 8(2), 29-39. https://doi.org/10.2304/rcie.2013.8.2.132

Davidovitch, N., \& Shiller, Z. (2014). Compensation Criteria In Higher Education In Israel And Elsewhere: Evaluation Of Research And Teaching Outcomes. Journal of International Education Research (JIER), 10(4), 279-294. https://doi.org/10.19030/jier.v10i4.8867

Dhawan, S. (2020). Online Learning: A Panacea in the Time of COVID-19 Crisis. Journal of Educational Technology Systems, 49(1), 5-22. https://doi.org/10.1177/0047239520934018

Domenici, V. (2020). Distance Education in Chemistry during the Epidemic Covid-19. Substantia, 4(1), 961. https://doi.org/10.13128/Substantia-961

Eckhaus, E., \& Davidovitch, N. (2019). Technology-supported teaching: Technological progress or a sham? European Journal of Educational Research, 8(3), 697-702. ISSN: $2165-8714$. https://doi.org/10.12973/eu-jer.8.3.697

Eyal, L. (2010). The reciprocity between learning-content management system (LCMS) and the assessment of learners in e-learning courses. Department of Information Science, 1-5.

Hannula, M. S. (2006). Motivation in mathematics: Goals reflected in emotions. Educational studies in mathematics, 63(2), 165-178. https://doi.org/10.1007/s10649-005-9019-8

Irvine, J. (2018). A Framework for Comparing Theories Related to Motivation in Education. Research in Higher Education Journal, 35.

Joubert, M. (2013). Using digital technologies in mathematics teaching: Developing an understanding of the landscape using three "grand challenge" themes. Educational Studies in Mathematics, 82(2), 341-359. https://doi.org/10.1007/s10649-012-9430-X 
Katz, A., \& Te'eni, D. (2014). The role of communication complexity in adaptive contextualization. IEEE Transactions on Professional Communication, 57(2), 98-112. https://doi.org/10.1109/TPC.2014.2312454

Katz, A., \& Kedem-Yemini, S. (2021). From Classrooms to Zoom Rooms: Preserving Effective Communication in Distance Education. Journal of Information Technology Case and Application Research, 23(3), 1-40. https://doi.org/10.1080/15228053.2021.1922248

Kaniel, S. (2006). Education for thinking: Cognitive education for the control of consciousness. Raanana: Ramot. [in Hebrew]

Kidd, T. T., \& Chen, I. (Eds.). (2011). Ubiquitous Learning: Strategies for Pedagogy, Course Design and Technology. IAP.

Kruse, K., \& Keil, J. (2000). Technology-based training: The art and science of design, development, and delivery. Centers for Teaching and Technology, 2, 187.

Laborde, C., \& Straesser, R. (2010). Place and use of new technology in the teaching of mathematics: ICMI activities in the past 25 years. Mathematics Education, 42(1), 121-133. https://doi.org/10.1007/s11858-009-0219-z

Melamed, U. (2013). Implementing information skills as a route to significant learning. Mofet Institute. [in Hebrew]

Nachmias, R., \& Mioduser, D. (2001). Integrating the Internet in education. Eureka, 14, 6-16. [in Hebrew] https://doi.org/10.1023/A:1011367212148

Nir Gal, O. (2000). Distance learning: The role of the teacher as a facilitator in the virtual learning environment. Flight and Act, 6, 103-129. [in Hebrew]

Resta, P., \& Shonfeld, M. (2013). A study of trans-national learning teams in a virtual world. In Society for Information Technology \& Teacher Education International Conference. Association for the Advancement of Computing in Education (AACE), 2932-2940.

Richard, R., \& Desi, A. (2011). Internal Motivation and External Motivation: Classical Definitions and New Directions. Echo of Education, 7, 62-68. [in Hebrew]

Ross, M., Perkins, H., \& Bodey, K. (2016). Academic motivation and information literacy self-efficacy: The importance of a simple desire to know. Library \& Information Science Research, 38(1), 2-9. https://doi.org/10.1016/j.lisr.2016.01.002

Schmeeckle, M. (2003). Online training: An evaluation of the effectiveness and efficiency of training law enforcement personnel over the Internet. Journal of Science Education and Technology, 12(3), 205-260. https://doi.org/10.1023/A:1025028806189

Shneiderman, B., \& Mayer, R. (1979). Syntactic/semantic interactions in programmer behavior: A model and experimental results. International Journal of Computer \& Information Sciences, 8(3), 219-238. https://doi.org/10.1007/BF00977789

Sue, C., Elizabeth, B., Amanda, H., \& Graham W. (2005). Effective e-learning for health professionals and students-barriers and their solutions. A systematic review of the literature-findings from the HeXL project. Health Information and Libraries Journal, 22(s2), 20-32. https://doi.org/10.1111/j.1470-3327.2005.00614.x

Sun, P. C., Tsai, R. J., Finger, G., Chen, Y. Y., \& Yeh, D. (2008). What drives a successful e-learning? An empirical investigation of the critical factors influencing learner satisfaction. Computers \& Education, 50(4), 1183-1202. https://doi.org/10.1016/j.compedu.2006.11.007

Tzur, S., Katz, A., \& Davidovitch, N. (2021). Learning Supported by Technology: Learning effectiveness with educational software. European Journal of Educational Research, 10(3), 1137-1156. ISSN: 2165-8714. https://doi.org/10.12973/eu-jer.10.3.1139

Trow, M. (1973). Problems in the Transition from Elite to Mass Higher Education. Carnegie Commission on Higher Education. Berkeley, Calif, 57-73.

Van Rosmalen, L., Van Der Horst, F. C., \& Van der Veer, R. (2016). From secure dependency to attachment: Mary Ainsworth's integration of Blatz's security theory into Bowlby's attachment theory. History of Psychology, 19(1), 22. https://doi.org/10.1037/hop0000015

Waldman, N. (2007). Only the enthusiasts hold the baton - Is that so? Teacher-teachers eager to improve teaching with the help of the computer. In college, 19, 403-415. [in Hebrew] 
Weiser, O., Blau, I., \& Eshet-Alkalai, Y. (2016). Synchronous face-to-face learning and in one- and two-way videoconferencing: The role of pedagogy media, personality factors, and level of media naturalness. Open University. [in Hebrew]

Yuen, H. K. A., \& Ma, W. K. W. (2008). Exploring teacher acceptance of e-learning technology. Asia-Pacific Journal of Teacher Education, 36(3), 229-243. https://doi.org/10.1080/13598660802232779

\section{Copyrights}

Copyright for this article is retained by the author(s), with first publication rights granted to the journal.

This is an open-access article distributed under the terms and conditions of the Creative Commons Attribution license (http://creativecommons.org/licenses/by/4.0/). 